\title{
Structural Characterization of Two Polymorphs of 1-(4-Methylpyridin-2-yl)thiourea and Two Derived 2-Aminothiazoles
}

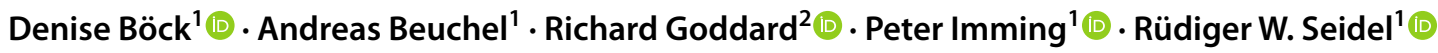

Received: 11 June 2020 / Accepted: 12 September 2020 / Published online: 1 October 2020

(c) The Author(s) 2020

\begin{abstract}
Two polymorphic forms of 1-(4-methylpyridin-2-yl)thiourea (1) and the crystal and molecular structures of the 2-aminothiazoles $N$-(4-methylpyridin-2-yl)-4-(pyridin-2-yl)thiazol-2-amine (2) and $N$-(4-methylpyridin-2-yl)-4-(pyrazin-2-yl) thiazol-2-amine (3), derived from 1 and the respective $\alpha$-bromoketone via the Hantzsch reaction, are described. Both polymorphic forms $\mathbf{1} \boldsymbol{\alpha}$ (space group $P 2_{1} / c, Z=4$ ) and $\mathbf{1 \beta}$ (space group $P 2_{1} / n, Z=8$ ) crystallize in the monoclinic system but exhibit distinctly different intermolecular hydrogen bonding patterns. Compound $\mathbf{2}$ (orthorhombic, space group $P c a 2_{1}, Z=8$ ) forms polymeric $\mathrm{N}-\mathrm{H} \cdots \mathrm{N}$ hydrogen-bonded zigzag tapes in the polar crystal structure, with a significant twisting between the thiazole and pyridine rings. In contrast, the crystal structure of $\mathbf{3}$ (monoclinic, space group $P 2_{1} / c, Z=4$ ) features nearly planar centrosymmetric $\mathrm{N}-\mathrm{H} \cdots \mathrm{N}$ hydrogen-bonded dimers, which are laterally joined through long $\mathrm{C}-\mathrm{H} \cdots \mathrm{N}$ contacts, affording a $\pi \cdots \pi$ stacked layered structure.
\end{abstract}

\section{Graphic Abstract}

Two polymorphs of 1-(4-methylpyridin-2-yl)thiourea and the crystal and molecular structures of two 2-aminothiazoles, derived from 1-(4-methylpyridin-2-yl)thiourea and $\alpha$-bromoketones via Hantzsch reaction, are reported.

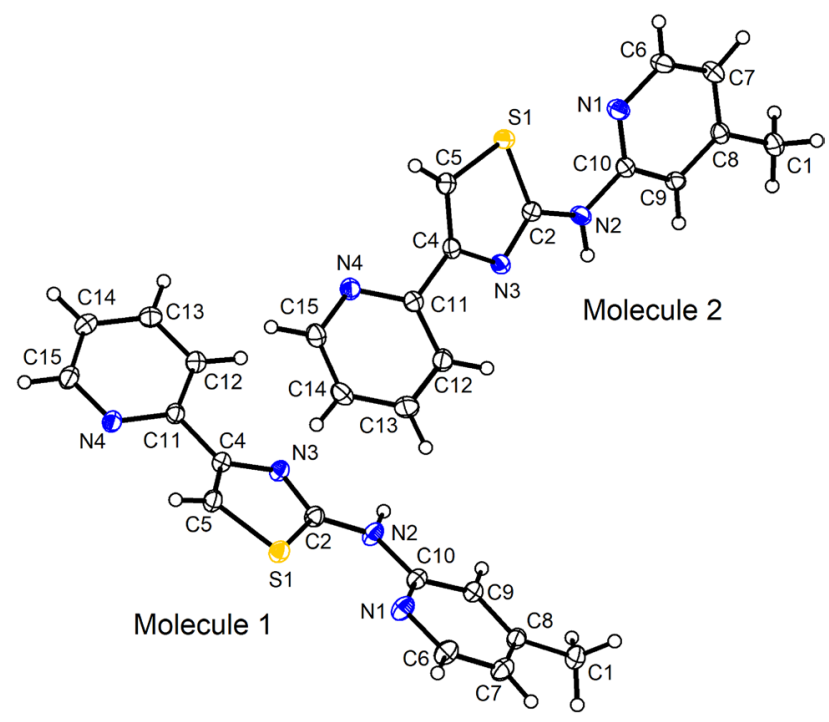

Keywords 1-(4-Methylpyridin-2-yl)thiourea $\cdot 2$-Aminothiazoles $\cdot$ Hantzsch reaction $\cdot$ Hydrogen bonding $\cdot$ Polymorphism . Crystal structure

Rüdiger W. Seidel

ruediger.seidel@pharmazie.uni-halle.de

Extended author information available on the last page of the article 


\section{Introduction}

The 2-aminothiazole moiety is a synthetically flexible and pharmacologically promising scaffold in medicinal chemistry, and a number of drugs containing a 2-aminothiazole4-subsituted moiety, e.g. cefdinir (antibiotic), mirabegron ( $\beta_{3}$ adrenergic agonist) or the tyrosine kinase inhibitor dasatinib, are on the market. In recent years, anticancer, antiepileptic, neuroprotective, antidiabetic, antihypertensive, anti-inflammamory, antiviral, antibiotic and antileishmanial properties of 2-aminothiazoles were investigated [1].

$N, 4$-Diaryl substituted 2-aminothiazoles were prepared based on one of the ten scaffolds with antileishmanial properties from a screening of 200,000 compounds [2]. Other microorganisms that are inhibited by this class of compounds include plasmodia [3] and mycobacteria [4]. For mycobacteria, the Tuberculosis Antimicrobial Acquisition and Coordinating Facility discovered an aminothiazole cluster of active compounds that formed the basis of an extensive structure-activity relationship (SAR) study [5]. Makam and Kannan showed that several substituted 2-aminothiazole derivatives exhibited antimycobacterial activity against Mycobacterium tuberculosis, $\mathrm{H}_{37} \mathrm{Rv}$, with minimum inhibitory concentration (MIC) values of $6.25-12.50 \mu \mathrm{M}$ and proposed that these may be targeting the KasA protein in turn disturbing the cell wall biosynthesis by obstructing mycolic acid synthesis [6]. Another study explored structure-activity relationships for 2-aminothiazoles as potassium channel blockers [7], an undesirable pharmacological effect in most cases, which needs to be prevented by modification of the substitution pattern on the 2-aminothiazole moiety. While $N$-alkyl and $N$-aryl 2-aminothiazoles are distinguished by therapeutically very desirable acitivities, they are also known to be cytotoxic [5]. This is most likely due to the unsubstituted 5-position, which unspecifically engages in redox reactions in biochemical pathways. In the course of our ongoing investigations towards reduced toxicity of this compound class, we structurally characterized 2-aminothiazoles by X-ray crystallography to gain information on the conformational preferences in the solid-state. The extent of the conjugated system and the steric accessibility of the sulfur atom and 5-position is expected to have an influence on the stability, particularly with regard to oxidation.

Synthesis of 2-amino-4-substituted thiazoles can be accomplished via different routes [8]. Hantzsch synthesis from $\alpha$-haloketones and thiourea derivatives in polar solvents is a general method $[9,10]$. From 1-(4-methylpyridin-2-yl)thiourea (1) and the respective $\alpha$-bromoketone, we synthesized the two 2-aminothiazoles $N$-(4-methylpyridin2-yl)-4-(pyridin-2-yl)thiazol-2-amine (2) and $N$-(4-methylpyridin-2-yl)-4-(pyrazin-2-yl)thiazol-2-amine (3) through Hantzsch synthesis (Scheme 1). Compound $\mathbf{2}$ is contained in the Stasis Box (Medicines for Malaria Venture, MMV, Geneva, Switzerland) as MMV006357 and was identified as an antimycobacterial $[4,11]$ agent and potential drug candidate for eumycetoma [12]. Although coordination compounds bearing 2 as ligand were reported more than 40 years ago [13], to the best of our knowledge and based on a WebCSD search in June 2020 [14], small molecule crystal structures of $\mathbf{2}$, its pyrazine derivative $\mathbf{3}$ and the starting thiourea derivative 1 have not been reported so far. Likewise, a search of the Protein Data Bank [15] yielded no structures containing $\mathbf{2}$ or $\mathbf{3}$ as ligands. Herein, we describe the structures of two polymorphs of $\mathbf{1}$, henceforth named $\mathbf{1} \boldsymbol{\alpha}$ and $\mathbf{1 \beta}$, and the crystal and molecular structures of 2-aminothiazoles $\mathbf{2}$ and $\mathbf{3}$, as determined by X-ray crystallography.

\section{Experimental Section}

\section{General}

Starting materials were purchased and used as received. Solvents were of analytical grade. The syntheses of 1-benzoyl-3-(4-methylpyridin-2-yl)thiourea [16] and 2-bromo-1(pyridin-2-yl)ethanone hydrobromide [17] can be found in the literature.
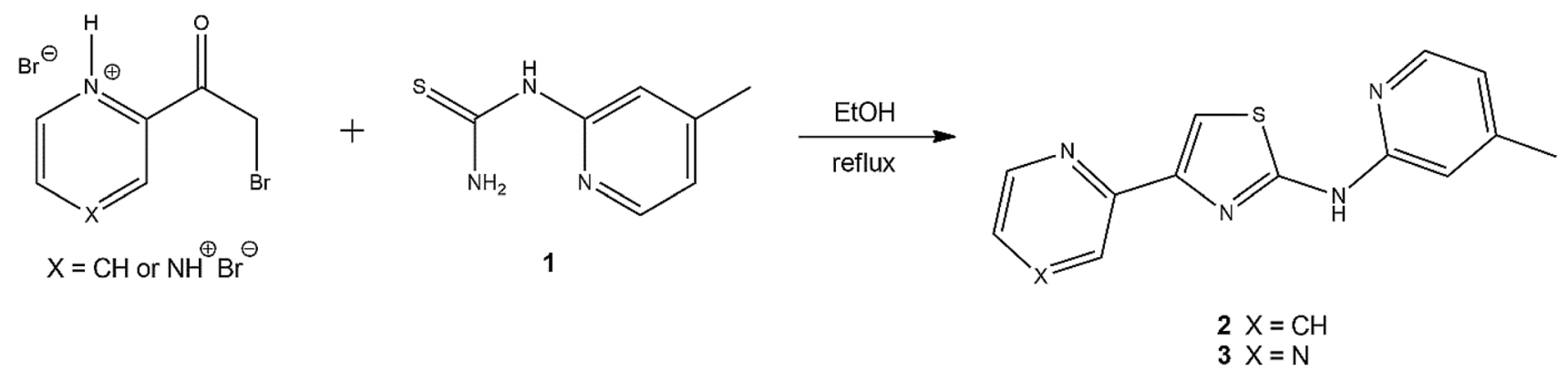

Scheme 1 Synthesis of aminothiazoles $\mathbf{2}$ and $\mathbf{3}$ from $\mathbf{1}$ and the respective $\alpha$-bromoketone 


\section{Physical Methods}

${ }^{1} \mathrm{H}$ and ${ }^{13} \mathrm{C}$ NMR spectra were recorded at room temperature on a Varian INOVA 500 NMR spectrometer. The residual solvent signals of DMSO- $d 6\left(\delta_{1 \mathrm{H}}=2.50 \mathrm{ppm}\right.$, $\left.\delta_{13 \mathrm{C}}=39.51 \mathrm{ppm}\right)$ were used to reference the spectra ( $\mathrm{s}=$ singlet, bs = broad singlet, $\mathrm{d}=$ doublet, $\mathrm{dd}=$ double doublet). The high-resolution mass spectrum was measured on a Bruker Daltonics Apex III FT-ICR mass spectrometer.

\section{Synthesis and Crystallization}

\section{1-(4-Methylpyridin-2-yl)thiourea (1)}

Compound $\mathbf{1}$ was synthesized by adapting a literature protocol [18]. $7.4 \mathrm{~mL}$ of $1 \mathrm{~N}$ aqueous $\mathrm{NaOH}$ were added to a stirred suspension of 1-benzoyl-3-(4-methylpyridin-2-yl)thiourea $(2.00 \mathrm{~g}, 7.37 \mathrm{mmol})$ in $15 \mathrm{~mL}$ of methanol. The mixture was then heated to reflux for $1 \mathrm{~h}$. After cooling to room temperature, a white solid formed, which was separated by filtration, washed with deionized water and dried over $\mathrm{P}_{2} \mathrm{O}_{5}$ in a vacuum desiccator to yield $1.00 \mathrm{~g}$ of $1(5.98 \mathrm{mmol}$, $81 \%$ ). Physical properties were in agreement with those reported in the literature [19]. Crystals of $\mathbf{1} \boldsymbol{\alpha}$ suitable for X-ray diffraction were obtained by recrystallization from methanol, and those of $\mathbf{1 \beta}$ were grown from a solution in $\mathrm{CDCl}_{3}$ by slow evaporation of the solvent.

\section{$N$-(4-Methylpyridin-2-yl)-4-(pyridin-2-yl)thiazol-2-amine (2)}

Compound 2 was synthesized following a modified literature procedure [20]. Compound $1(83 \mathrm{mg}, 0.50 \mathrm{mmol})$ and 2-bromo-1-(pyridin-2-yl)ethanone hydrobromide (140 mg, $0.50 \mathrm{mmol}$ ) were dissolved in $5 \mathrm{~mL}$ of ethanol and triethylamine $(0.1 \mathrm{~mL})$ was added. The reaction mixture was refluxed for $2 \mathrm{~h}$. Subsequently, the solvent was removed using a rotary evaporator. The residue was taken up in $10 \mathrm{~mL}$ of a saturated $\mathrm{K}_{2} \mathrm{CO}_{3}$ solution and extracted three times with ethyl acetate. The combined organic layers were washed with brine and dried over $\mathrm{MgSO}_{4}$. The solvent was removed under reduced pressure and the crude product recrystallized from methanol. Yield: $54 \mathrm{mg}(0.20 \mathrm{mmol}, 40 \%)$. Spectroscopic properties were in agreement with those reported in the literature $[2,20]$. Crystals for X-ray diffraction were taken from the mother liquor.

\section{$N$-(4-Methylpyridin-2-yl)-4-(pyrazin-2-yl)thiazol-2-amine (3)}

Compound 3 was prepared in analogy to 2 from 1 and 2-bromo-1-(pyrazin-2-yl) ethanone hydrobromide [21] (note that the compound was not named hydrobromide by these authors), which was synthesized from acetylpyrazine (0.50 g, $4.00 \mathrm{mmol})$ using 2-pyrrolidinone hydrotribromide
( $2.18 \mathrm{~g}, 4.4 \mathrm{~mol})$ as reagent and used in situ without purification. Yield (based on 1): $75 \mathrm{mg}(0.28 \mathrm{mmol}, 7 \%) .{ }^{1} \mathrm{H}$ NMR (500 MHz, DMSO- $d 6): \delta=11.46(\mathrm{~s}, 1 \mathrm{H}), 9.14(\mathrm{~d}$, $J=1.5 \mathrm{~Hz}, 1 \mathrm{H}), 8.64(\mathrm{dd}, J=2.5,1,5 \mathrm{~Hz}, 1 \mathrm{H}), 8.55(\mathrm{~d}$, $J=2.5 \mathrm{~Hz}, 1 \mathrm{H}), 8.17(\mathrm{~d}, J=5.2 \mathrm{~Hz}, 1 \mathrm{H}), 7.75(\mathrm{~s}, 1 \mathrm{H}), 6.89$ (bs, $1 \mathrm{H}), 6.79(\mathrm{dd}, J=5.2 \mathrm{~Hz}, 1 \mathrm{H}), 2.28(\mathrm{~s}, 3 \mathrm{H}) \mathrm{ppm} ;{ }^{13} \mathrm{C}$ NMR (126 MHz, DMSO- $d 6$ ): $\delta=160.5,151.8,148.7,147.7$, 146.2, 146.0, 144.4, 143.3, 141.4, 117.7, 111.7, 110.7, 20.7 ppm. HRMS(ESI): calcd. for $\mathrm{C}_{13} \mathrm{H}_{11} \mathrm{~N}_{5} \mathrm{~S}[\mathrm{M}+\mathrm{H}]^{+}$ 270.0813, found 270.0806. Crystals for X-ray diffraction were taken from the mother liquor.

\section{Crystal Structure Determination}

The X-ray intensity data for $\mathbf{1} \boldsymbol{\alpha}$ and $\mathbf{3}$ were measured on a Bruker AXS Apex II diffractometer, equipped respectively with an Incoatec I $\mu \mathrm{S}$ microfocus X-ray source and a FR591 rotating anode radiation source. The diffraction data for $\mathbf{2}$ were collected on an Enraf-Nonius KappaCCD diffractometer with a FR591 rotating anode. The SAINT software was used to perform data reductions [22]. The intensity measurements for $\mathbf{1 \beta}$ were carried out on the P11 beamline at the PETRA III light source (DESY, Hamburg) at an $\mathrm{X}$-ray energy of $22.0 \mathrm{keV}$. The primary beam intensity was monitored continuously and stored during the experiment. The P11 X-ray optics consisted of a liquid nitrogen-cooled $\mathrm{Si}(111)$ and $\mathrm{Si}(113)$ double-crystal monochromator and one vertical and two horizontal deflecting $X$-ray mirrors. The source brilliance at the crystal was $1.7 \times 10^{12}$ photons per second. The data were collected using a $200 \mu \mathrm{m}$ beam on a PILATUS 6 M-0109 detector (Dectris Ltd, Baden, Switzerland) [23] at a distance of $163.4 \mathrm{~mm}$ from the crystal. The 20-bit dynamic range of the PILATUS $6 \mathrm{M}$ detector allowed for collection of weak high-order and stronger loworder reflections at the same time in one run. The crystal was rotated by $360^{\circ}$ in steps of $0.5^{\circ}$ with an exposure of $0.250 \mathrm{~s}$ per frame with a filter transmission of 0.1 using the P11 Crystallography Control graphical user interface at the P11 beamline [24]. The data were processed with the XDS program package [25]. Absorption corrections were carried out with SADABS [26].

The crystal structures were solved with SHELXT-2018/1 [27] and refined with SHELXL-2018/3 [28]. The structure of $\mathbf{1 \beta}$ was refined using aspherical atomic scattering factors [29] and corrected for dispersion according to Kissel and Pratt [30]. Asphericity parameters were generated by the APEX3 software (IDEAL) [31]. Anisotropic displacement parameters were introduced for all non-hydrogen atoms. For $\mathbf{1 \alpha}, \mathbf{2}$ and $\mathbf{3}$, carbon-bound hydrogen atoms were placed at geometrically calculated positions with $\mathrm{C}_{\text {aromatic }}-\mathrm{H}=0.95 \AA$ and $\mathrm{C}_{\text {methyl }} \mathrm{H}=0.98 \AA$ and refined with the appropriate riding model. Methyl groups were allowed to rotate to match the underlying electron density maxima. Hydrogen atoms 
attached to nitrogen were localized in difference electron density maps and, for $\mathbf{1} \boldsymbol{\alpha}, \mathbf{2}$ and $\mathbf{3}$, refined with the $\mathrm{N}-\mathrm{H}$ bond lengths restrained to a target value of 0.88(2) $\AA$. $U_{\text {iso }}(\mathrm{H})=1.2 U_{\text {eq }}(\mathrm{C}, \mathrm{N})$ (1.5 for methyl groups) was applied for all hydrogen atoms. Packing indices were calculated with PLATON [32]. Structure pictures were generated with Diamond [33] and Mercury [34]. Crystal data and refinement details for $\mathbf{1} \alpha, \mathbf{1 \beta}, \mathbf{2}$ and $\mathbf{3}$ are listed in Table 1.

\section{Results and Discussion}

\section{Polymorphic Forms of 1}

Two monoclinic crystal forms of $\mathbf{1}$ were encountered. $\mathbf{1} \boldsymbol{\alpha}$ with one molecule in the asymmetric unit $\left(Z^{\prime}=1\right)$ formed upon recrystallization from methanol, and $\mathbf{1 \beta}$ with two crystallographically unique molecules $\left(Z^{\prime}=2\right)$ crystallized from a solution of the compound in $\mathrm{CDCl}_{3}$. Figure 1 shows displacement ellipsoid plots of both structures, and Table 2 compares selected bond lengths and torsion angles. The bond lengths are comparable with those in the parent 1-(pyridine-2-yl)thiourea (CSD refcode: HIRPAA) [35]. Both $\mathbf{1 \alpha}$ and $\mathbf{1 \beta}$ have in common a six-membered ring intramolecular $\mathrm{N}-\mathrm{H} \cdots \mathrm{N}$ hydrogen bond between the primary amino group on the thiourea moiety and the pyridine nitrogen atom, which is in accord with Etter's second hydrogen bond rule for organic compounds, namely that sixmembered ring intramolecular hydrogen bonds form in preference to intermolecular hydrogen bonds [36]. The graphset assignment for this hydrogen bond motif is $\mathrm{S}(6)$. This requires a synperiplanar conformation between the pyridine nitrogen atom and the thiocarbonyl carbon atom $\mathrm{C} 1$, and likewise between the pivot carbon atom $\mathrm{C} 2$ of the pyridine ring and the primary amino group. The same intramolecular hydrogen bond and molecular conformation was found in HIRPAA. Like in HIRPAA, the molecule is virtually planar in $\mathbf{1 \alpha}$ (r.m.s. deviation $0.0234 \AA$ for the non-hydrogen atoms). In contrast, the two unique molecules in $\mathbf{1 \beta}$ deviate markedly from planarity by a tilt of the thiourea group from the plane of the pyridine ring, as revealed by the respective angles between the mean planes of the two groups [molecule 1: $14.16(5)^{\circ}$; molecule $2: 18.08(5)^{\circ}$ ] and the torsion angles listed in Table 2.

Table 1 Crystal data and refinement details for $1 \alpha, \mathbf{1 \beta}, 2$ and 3

\begin{tabular}{|c|c|c|c|c|}
\hline & $1 \alpha$ & $1 \beta$ & 2 & 3 \\
\hline Empirical formula & $\mathrm{C}_{7} \mathrm{H}_{9} \mathrm{~N}_{3} \mathrm{~S}$ & $\mathrm{C}_{7} \mathrm{H}_{9} \mathrm{~N}_{3} \mathrm{~S}$ & $\mathrm{C}_{14} \mathrm{H}_{12} \mathrm{~N}_{4} \mathrm{~S}$ & $\mathrm{C}_{13} \mathrm{H}_{11} \mathrm{~N}_{5} \mathrm{~S}$ \\
\hline$M_{\mathrm{r}}$ & 167.23 & 167.23 & 268.34 & 269.33 \\
\hline$T(\mathrm{~K})$ & $100(2)$ & $100(2)$ & $100(2)$ & $100(2)$ \\
\hline$\lambda(\AA)$ & 0.71073 & 0.6199 & 0.71073 & 1.54178 \\
\hline Crystal system & Monoclinic & Monoclinic & Orthorhombic & Monoclinic \\
\hline Space group & $P 2_{1} / c$ (No. 14$)$ & $P 2_{1} / n$ (No. 14$)$ & $P_{c a 2}$ (No. 29) & $P 2_{1} / c$ (No. 14$)$ \\
\hline$a(\AA)$ & $6.9526(13)$ & $8.2312(16)$ & $7.3353(7)$ & $7.3009(2)$ \\
\hline$b(\AA)$ & $14.473(3)$ & $16.095(3)$ & $26.7342(16)$ & $15.5664(4)$ \\
\hline$c(\AA)$ & $8.1672(15)$ & $12.240(3)$ & 13.1949(9) & $10.8403(3)$ \\
\hline$\beta\left(^{\circ}\right)$ & $102.395(4)$ & $97.10(3)$ & 90 & $96.320(1)$ \\
\hline$V\left(\AA^{3}\right)$ & $802.7(3)$ & 1609.2(6) & $2587.6(3)$ & $1224.50(6)$ \\
\hline$Z, Z^{\prime}$ & 4,1 & 8,2 & 8,2 & 4,1 \\
\hline$V /$ molecule $\left(\AA^{3}\right)$ & 200.7 & 201.2 & 323.5 & 306.1 \\
\hline$\rho_{\text {calc }}\left(\mathrm{g} \mathrm{cm}^{-3}\right)$ & 1.384 & 1.381 & 1.378 & 1.461 \\
\hline$\mu\left(\mathrm{mm}^{-1}\right)$ & 0.337 & 0.230 & 0.241 & 2.290 \\
\hline$F(000)$ & 352 & 704 & 1120 & 560 \\
\hline Crystal size (mm) & $0.168 \times 0.106 \times 0.021$ & $0.156 \times 0.103 \times 0.091$ & $0.170 \times 0.120 \times 0.110$ & $0.223 \times 0.196 \times 0.120$ \\
\hline$\theta$ range $\left(^{\circ}\right)$ & $2.815-30.982$ & $1.832-26.193$ & $2.880-33.098$ & $4.992-73.002$ \\
\hline Reflections collected / unique & $20,352 / 2538$ & $30,415 / 4753$ & $59,604 / 9807$ & 42,832 / 2360 \\
\hline$R_{\mathrm{int}}$ & 0.0642 & 0.0226 & 0.0542 & 0.0427 \\
\hline Observed reflections $[I>2 \sigma(I)]$ & 2109 & 4542 & 8482 & 2122 \\
\hline Goodness-of-fit on $F^{2}$ & 1.195 & 1.060 & 1.081 & 1.215 \\
\hline Parameters/restraints & $110 / 3$ & $256 / 0$ & $359 / 3$ & $176 / 1$ \\
\hline$R_{1}[I>2 \sigma(I)]$ & 0.0420 & 0.0248 & 0.0425 & 0.0410 \\
\hline$w R_{2}$ (all data) & 0.1078 & 0.0702 & 0.1014 & 0.1129 \\
\hline$\Delta \rho_{\max }, \Delta \rho_{\min }\left(\mathrm{e}^{-3}\right)$ & $0.601,-0.480$ & $0.583,-0.316$ & $0.367,-0.293$ & $0.278,-0.405$ \\
\hline
\end{tabular}


Fig. 1 a Hydrogen-bonded association of two symmetryrelated molecules in $1 \alpha$ and b of the two crystallographically distinct molecules in $\mathbf{1 \beta}$. Symmetry code: (a) x, $0.5-\mathrm{y}$, $0.5+$ z. Displacement ellipsoids are drawn at the $50 \%$ probability level. Hydrogen atoms are shown as small spheres of arbitrary radii. Dashed lines represent hydrogen bonds

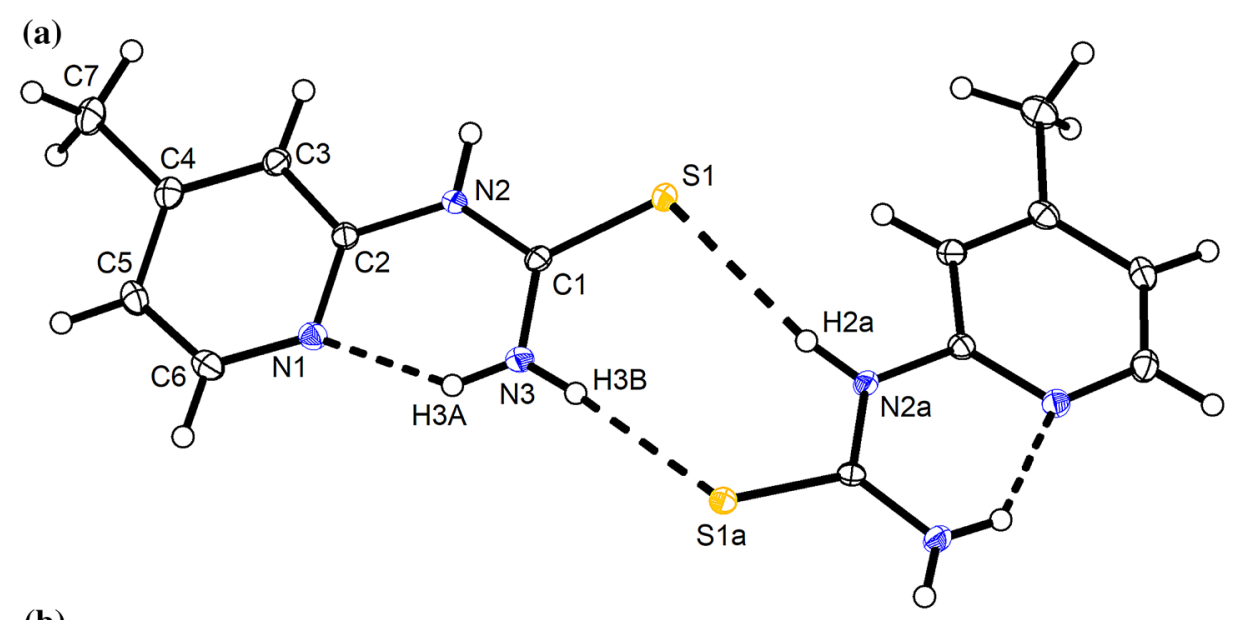

(b)

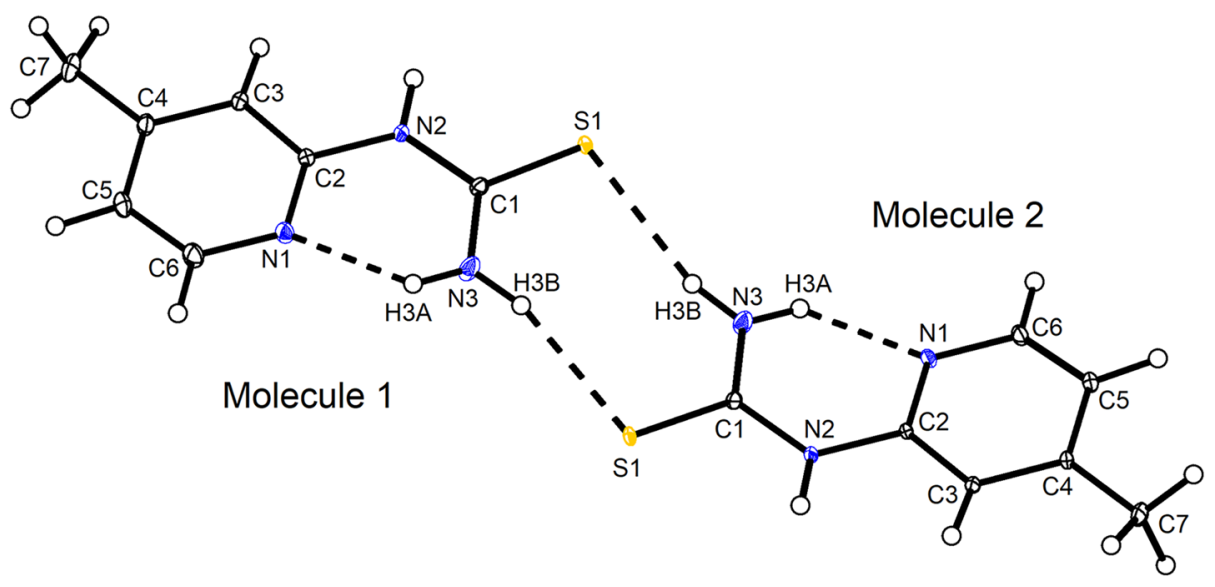

Table 2 Selected bond lengths $(\AA)$ and torsion angles $\left(^{\circ}\right)$ for $\mathbf{1} \boldsymbol{\alpha}$ and $\mathbf{1 \beta}$

\begin{tabular}{llll}
\hline & $\mathbf{1} \boldsymbol{\alpha}$ & $\mathbf{1 \beta}$ & \\
\cline { 3 - 4 } & & Molecule 1 & Molecule 2 \\
\hline $\mathrm{C} 1-\mathrm{S} 1$ & $1.7011(17)$ & $1.7038(7)$ & $1.7047(7)$ \\
$\mathrm{C} 1-\mathrm{N} 2$ & $1.355(2)$ & $1.3634(9)$ & $1.3644(8)$ \\
$\mathrm{C} 1-\mathrm{N} 3$ & $1.322(2)$ & $1.3206(9)$ & $1.3228(9)$ \\
$\mathrm{C} 2-\mathrm{N} 2$ & $1.403(2)$ & $1.4045(8)$ & $1.4069(8)$ \\
$\mathrm{N} 1-\mathrm{C} 2-\mathrm{N} 2-\mathrm{C} 1$ & $2.5(3)$ & $17.0(1)$ & $-19.48(10)$ \\
$\mathrm{N} 3-\mathrm{C} 1-\mathrm{N} 2-\mathrm{C} 2$ & $-2.8(3)$ & $-9.36(11)$ & $15.49(10)$ \\
\hline
\end{tabular}

$\mathbf{1 \alpha}$ and $\mathbf{1 \beta}$ exhibit distinctly different intermolecular hydrogen bonding patterns. Two self-complementary $\mathrm{N}-\mathrm{H} \cdots \mathrm{S}$ hydrogen bonding sites on each molecule, provided by the sulfur atom as hydrogen bond acceptor and each of the primary and secondary amino groups as hydrogen bond donor sites, can lead to three possible combinations with $R_{2}^{2}(8)$ motifs (Scheme 2) [37]. As shown in Fig. 1, $1 \alpha$ exhibits the asymmetric combination involving primary and secondary amino groups (type I), whereas $\mathbf{1 \beta}$ shows the symmetric combination formed solely by the primary amino groups (type II). Type I is also observed for the structure of HIRPAA. Table 3 lists geometric parameters of the hydrogen bonds in $\mathbf{1} \alpha$ and $\mathbf{1 \beta}$, which are as expected [35]. In $\mathbf{1} \alpha$, this hydrogen bond arrangement results in polymeric tapes extending through glide symmetry in the [001] direction (Fig. 2). In contrast, the secondary amino groups in $\mathbf{1 \beta}$ are directed towards sulfur atoms of adjacent hydrogen-bonded dimers in the crystal structure with $\mathrm{N} \cdots \mathrm{S}$ distances of ca. $3.4 \AA$ and significantly smaller $\mathrm{H} \cdots \mathrm{S}-\mathrm{C}$ angles than in $\mathbf{1} \boldsymbol{\alpha}$. The symmetric dimer in $\mathbf{1 \beta}$ exhibits local inversion symmetry in the crystal structure. Frustration between competing intermolecular interactions, such as hydrogen bonds, and close packing has been put forward as a possible explanation for the $Z^{\prime}>1$ phenomenon [38]. The crystal structures of both $1 \alpha$ and $\mathbf{1 \beta}$ belong to the same space group type (No. 14 ), which is available for densest packing of molecules of arbitrary shape. The packing index is $69.6 \%$ for $1 \alpha$ and $70.4 \%$ for $\mathbf{1} \boldsymbol{\beta}$, revealing a dense crystal packing in both forms [39]. It is worth noting that in spite of the different hydrogen bonding patterns, the calculated crystallographic density is almost the same for $\mathbf{1} \boldsymbol{\alpha}$ and $\mathbf{1 \beta}$ (Table 1). 


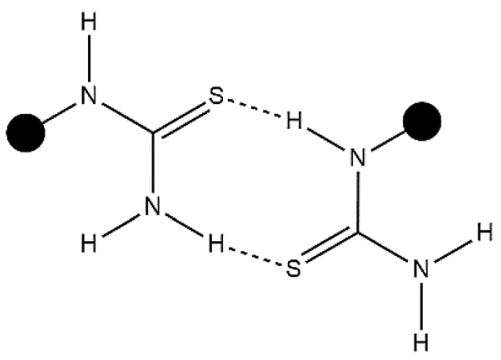

I<smiles>[1H]NC1=[SH]CCN(C)C(N[CH])=[SH][CH]1</smiles>

II<smiles>CN(C)C1=[SH]CC(N)N(C)CS1</smiles>

III

Scheme 2 Possible $\mathrm{N}-\mathrm{H} \cdots \mathrm{S}$ hydrogen bond associations of $\mathbf{1}$ (the black circle represents 4-methylpyridin-2-yl) with $\mathrm{R}_{2}^{2}(8)$ motifs. 1 $\boldsymbol{\alpha}$ exhibits type I and $\mathbf{1 \beta}$ shows type II. Type III is not seen here

Table 3 Hydrogen bond parameters $\left(\AA{ }^{\circ}\right)$ for $\mathbf{1} \boldsymbol{\alpha}$ and $\mathbf{1 \beta}$

\begin{tabular}{|c|c|c|c|c|}
\hline & $d(D-H)$ & $d(H \cdots A)$ & $d(D \cdots A)$ & $<(D \mathrm{H} A)$ \\
\hline \multicolumn{5}{|l|}{$1 \alpha^{\mathrm{a}}$} \\
\hline $\mathrm{N} 2-\mathrm{H} 2 \cdots \mathrm{S} 1 \mathrm{a}$ & $0.880(15)$ & $2.462(16)$ & $3.3324(15)$ & $170(2)$ \\
\hline N3-H3A $\cdots \mathrm{N} 1$ & $0.873(16)$ & 1.961(19) & $2.670(2)$ & $137(2)$ \\
\hline $\mathrm{N} 3-\mathrm{H} 3 \mathrm{~B} \cdots \mathrm{S} 1 \mathrm{~b}$ & $0.872(15)$ & $2.485(16)$ & $3.3553(16)$ & $175(2)$ \\
\hline \multicolumn{5}{|l|}{$1 \beta^{\mathrm{b}}$} \\
\hline N31-H31A $\cdots$ N11 & $0.889(12)$ & $1.990(11)$ & $2.6844(10)$ & $134.0(10)$ \\
\hline N31-H31B $\cdots$ S12 & $0.922(12)$ & $2.443(12)$ & $3.3425(10)$ & $165.1(10)$ \\
\hline N32-H32A $\cdots$ N12 & $0.897(12)$ & $1.994(11)$ & $2.6970(9)$ & $134.2(10)$ \\
\hline N32-H32B $\cdots \mathrm{S} 11$ & $0.913(11)$ & $2.507(11)$ & $3.3977(9)$ & $165.0(9)$ \\
\hline
\end{tabular}

a Symmetry codes: (a) $\mathrm{x},-\mathrm{y}+1 / 2, \mathrm{z}-1 / 2$; (b) $\mathrm{x},-\mathrm{y}+1 / 2, \mathrm{z}+1 / 2$

${ }^{\mathrm{b}}$ The second integer indicates unique molecule 1 or 2 (cf. Fig. 1)

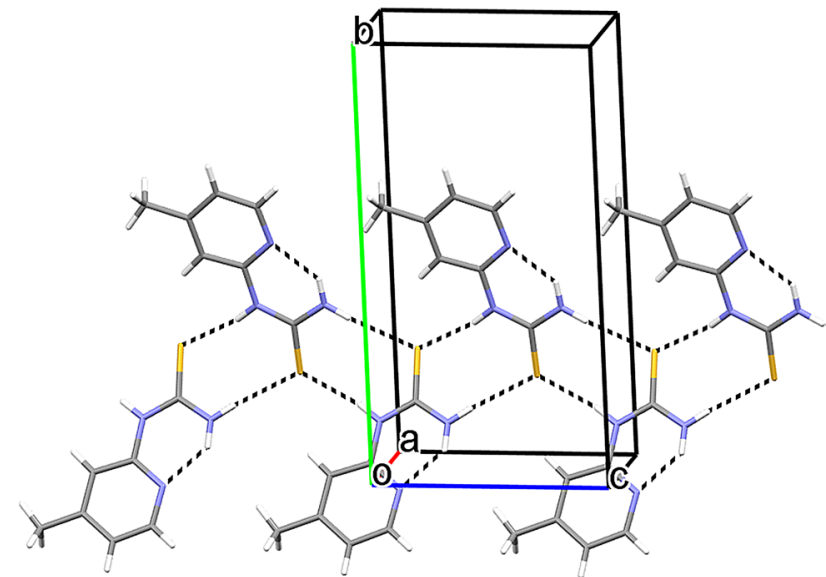

Fig. 2 Part of the crystal structure of $\mathbf{1} \boldsymbol{\alpha}$, showing hydrogen-bonded tapes of the molecules extending parallel to the crystallographic $c$ axis

\section{Crystal and Molecular Structures of $\mathbf{2}$ and $\mathbf{3}$}

Compound 2 crystallizes with two molecules in the asymmetric unit $\left(Z^{\prime}=2\right)$, as shown in Fig. 3. Selected bond lengths, bond angles and torsion angles are given in Table 4. In both molecules the thiazole sulfur atom S1 and the pivot carbon atom $\mathrm{C} 10$ of the pyridine ring as well as the pivot carbon atom of the thiazole ring $\mathrm{C} 2$ and the picoline nitrogen atom N1 are in a synperiplanar arrangement. The intramolecular $\mathrm{N} 1 \cdots \mathrm{S} 1$ distance is ca. $2.8 \AA$ in both molecules and the $\mathrm{C} 5-\mathrm{S} 1 \cdots \mathrm{N} 1$ angles are 161.5 and $160.1^{\circ}$ in molecule 1 and 2 , respectively. From the structural point of view, this can be interpreted as chalcogen bonds between the picoline nitrogen lone pairs and the $\sigma$ hole at the sulfur atoms opposite to the C5-S1 $\sigma$ bonds $[40,41]$. Interestingly, all 15 crystal structures of 2 -aminothiazoles with $N$-bonded heteroaromatic substituents containing a nitrogen atom in the 2-position in the Cambridge Structural Database (June 2020) [42] exhibit planar conformations with intramolecular N $\cdots$ S distances of 2.70(4) $\AA$ (mean) in spite of different crystal environments, including structures of dasatinib and nine of its solvates [43, 44], as well as thiazovivin, a small molecule tool for stem cell research [45]. In contrast, 41 crystal structures of 2-aminothiazoles with variously substituted $N$-phenyl groups contain molecules in which the two moieties are randomly orientated to one another. The absence of any classical or weak hydrogen bonds towards the picoline nitrogen N1 corroborates this view. The dihedral angles between the mean planes through the thiazole rings and those through the pyridine rings attached to $\mathrm{C} 4$ is $22.96(8)^{\circ}$ for molecule 1 and $37.53(6)^{\circ}$ for molecule 2 . Both molecules are thus significantly non-planar in this region. Clearly, the tilt between the pyridine ring and the thiazole ring should be disadvantageous for $\pi$ electron delocalisation, but appears to be outweighed by the formation of strong intermolecular $\mathrm{N}-\mathrm{H} \cdots \mathrm{N}$ hydrogen bonds between the amino group and the pyridine nitrogen atom N4 in the solid-state (Table 5). Molecule 1 and molecule 2 each form distinct hydrogen-bonded zigzag tapes extending in the [001] direction through glide symmetry (Fig. 4), resulting in a polar $c$ axis. The packing index is $69.0 \%$.

Figure 5 shows the molecular structure of $\mathbf{3}$, bearing a pyrazinyl group at $\mathrm{C} 4$ of the thiazole ring instead of a 
Fig. 3 Asymmetric unit of 2. Displacement ellipsoids are drawn at the $50 \%$ probability level. Hydrogen atoms are shown as small spheres of arbitrary radii

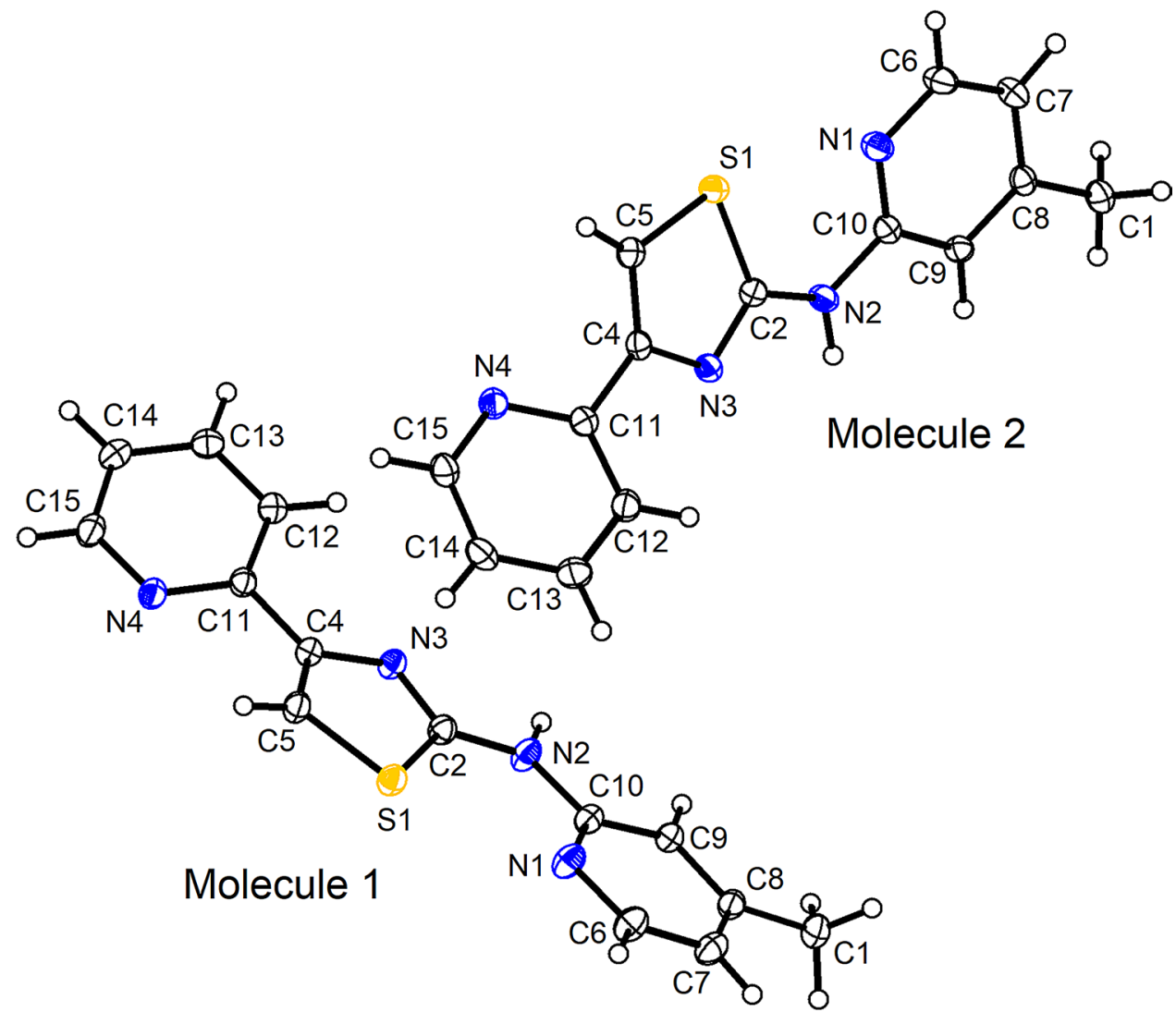

Table 4 Selected bond lengths, bond angles and torsion angles $\left(\AA{ }^{\circ}\right)$ for $\mathbf{2}$ and $\mathbf{3}$

\begin{tabular}{llll}
\hline & $\mathbf{2}$ & & $\mathbf{3}$ \\
\cline { 2 - 3 } & Molecule 1 & Molecule 2 & \\
\hline C2-N3 & $1.312(3)$ & $1.312(3)$ & $1.309(2)$ \\
C2-N2 & $1.363(3)$ & $1.370(3)$ & $1.367(2)$ \\
C2-S1 & $1.748(2)$ & $1.744(2)$ & $1.7480(17)$ \\
C4-C5 & $1.362(3)$ & $1.363(3)$ & $1.355(2)$ \\
C4-N3 & $1.379(3)$ & $1.379(3)$ & $1.389(2)$ \\
C4-C11 & $1.473(3)$ & $1.478(3)$ & $1.469(2)$ \\
C5-S1 & $1.732(2)$ & $1.724(2)$ & $1.7212(17)$ \\
N3-C2-S1 & $114.94(17)$ & $115.00(17)$ & $115.31(13)$ \\
C5-C4-N3 & $115.9(2)$ & $115.7(2)$ & $115.85(15)$ \\
C4-C5-S1 & $110.21(17)$ & $110.39(18)$ & $110.68(13)$ \\
C5-S1-C2 & $88.6(1)$ & $88.67(11)$ & $88.48(8)$ \\
C2-N3-C4 & $110.4(2)$ & $110.25(19)$ & $109.67(14)$ \\
S1-C2-N2-C10 & $-4.2(4)$ & $14.8(3)$ & $7.2(2)$ \\
N1-C10-N2-C2 & $-1.6(4)$ & $-4.3(3)$ & $-1.2(2)$ \\
C5-C4-C11-N4 & $-22.4(3)$ & $37.4(3)$ & $-5.6(3)$ \\
N3-C4-C11-C12 & $-23.3(3)$ & $36.7(3)$ & $-8.0(3)$ \\
\hline
\end{tabular}

2-pyridinyl group as in $\mathbf{2}$. Selected bond lengths, bond angles and torsion angles are listed in Table 4. Like $\mathbf{2}$, the thiazole sulfur atom $\mathrm{S} 1$ and the pivot carbon atom $\mathrm{C} 10$ of
Table 5 Hydrogen bond parameters $\left(\AA,^{\circ}\right)$ for $\mathbf{2}$ and $\mathbf{3}$

\begin{tabular}{lllll}
\hline & $d(D-\mathrm{H})$ & $d(\mathrm{H} \cdots A)$ & $d(D \cdots A)$ & $<(D \mathrm{H} A)$ \\
\hline $\mathbf{2}^{\mathrm{a}}$ & & & \\
$\mathrm{N} 21-\mathrm{H} 2 \_1 \ldots \mathrm{N} 41 \mathrm{a}$ & $0.88(2)$ & $2.01(2)$ & $2.893(3)$ & $177(3)$ \\
$\mathrm{N} 22-\mathrm{H} 2 \_2 \ldots \mathrm{N} 42 \mathrm{~b}$ & $0.88(2)$ & $2.10(2)$ & $2.979(3)$ & $177(3)$ \\
$\mathbf{3}^{\mathrm{b}}$ & & & & \\
$\mathrm{N} 2-\mathrm{H} 2 \ldots \mathrm{N} 5 \mathrm{a}$ & $0.878(15)$ & $2.053(15)$ & $2.928(2)$ & $174.2(19)$ \\
$\mathrm{C} 6-\mathrm{H} 6 \ldots \mathrm{N} 4 \mathrm{~b}$ & 0.95 & 2.98 & $3.906(2)$ & 165 \\
\hline & \\
a The second integer indicates unique molecule 1 or $2(c f$. Fig. 3).
\end{tabular}

the pyridine ring as well as the pivot carbon atom of the thiazole ring $\mathrm{C} 2$ and the picoline nitrogen atom $\mathrm{N} 1$ in $\mathbf{3}$ are in a synperiplanar orientation with an intramolecular S1 $\cdots \mathrm{N} 1$ distance of ca. $2.7 \AA$ with a $\mathrm{C} 5-\mathrm{S} 1 \cdots \mathrm{N} 1$ angle of $162.5^{\circ}$. Thus, the observed conformation appears to be a characteristic trait of the $N$-(4-methylpyridin-2-yl) thiazol-2-amine moiety and is possibly supported by an intramolecular chalcogen bond (vide supra). In contrast to 2 , the dihedral angle between the mean plane through the thiazole ring and that through the pyrazin ring attached to $\mathrm{C} 4$ is only $7.25(6)^{\circ}$. The supramolecular structure of $\mathbf{3}$ in the crystal is distinctly different from that in $\mathbf{2}$. Instead 
Fig. 4 Part of the crystal structure of 2, viewed approximately along the $a$ axis direction and b along the $c$ axis direction. Hydrogen atoms have been omitted for clarity. Dashed lines represent hydrogen bonds. Red and blue colour indicate distinct hydrogen-bonded tapes resulting from unique molecules 1 and 2, respectively ( $c f$. Fig. 3)

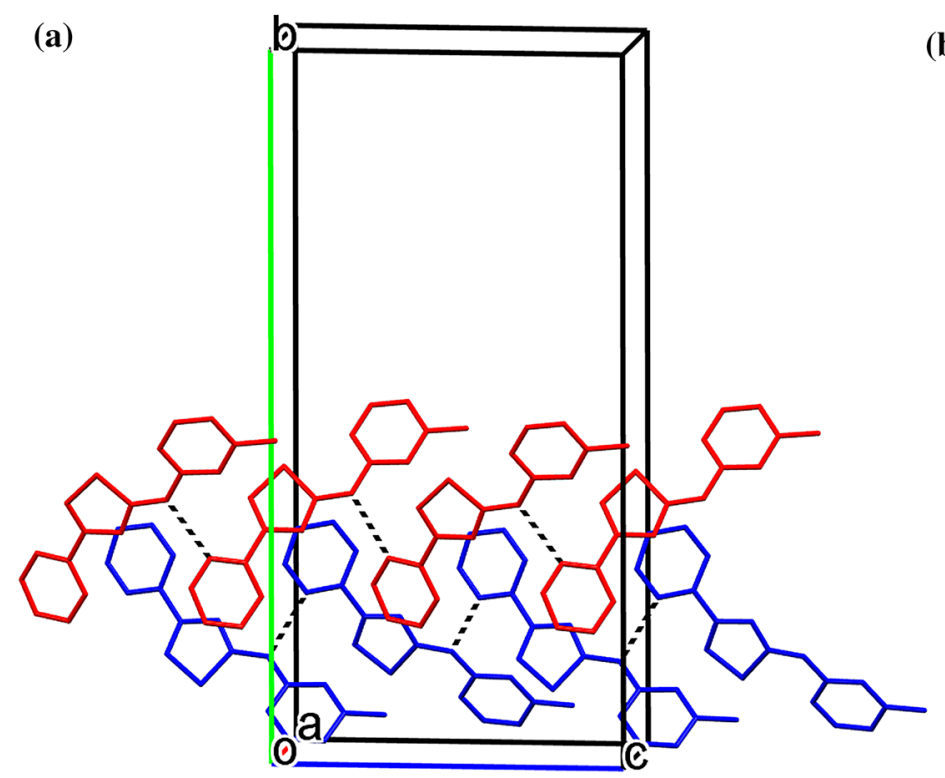

(b)

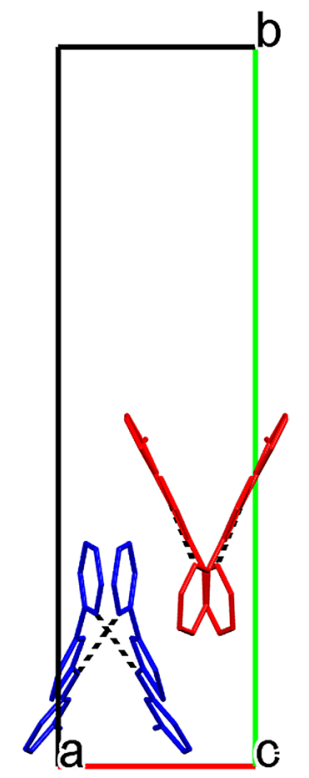

Fig. 5 Molecular structure of 3 in the crystal. Displacement ellipsoids are drawn at the $50 \%$ probability level. Hydrogen atoms are represented by small spheres of arbitrary radii

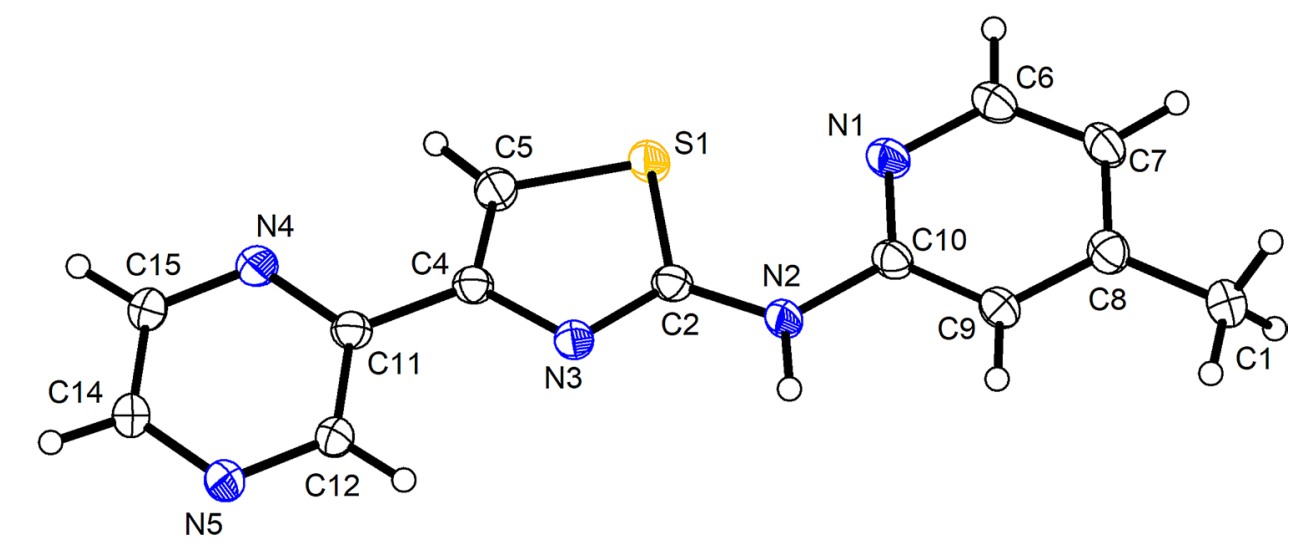

of the polymeric $\mathrm{N}-\mathrm{H} \cdots \mathrm{N}$ hydrogen-bonded assemblies observed in $\mathbf{2}$, the crystal structure of $\mathbf{3}$ is characterized by centrosymmetric dimers (Fig. 6). The amino group of each molecule forms a hydrogen bond to the pyrazine nitrogen atom in meta position to the thiazole ring, affording a $R_{2}^{2}(16)$ motif. The dimers so formed are laterally connected via $\mathrm{C}-\mathrm{H} \cdots \mathrm{N}$ interactions involving the opposite pyrazine nitrogen atom. Although the $\mathrm{H} \cdots A$ distance is longer than the sum of the van der Waals radii, the $<(D H A)$ angle (Table 5) supports the presence of weak cooperative $\mathrm{C}-\mathrm{H} \cdots \mathrm{N}$ hydrogen bonds [46]. The $\mathrm{N}-\mathrm{H} \cdots \mathrm{N}$ hydrogen bonds and long $\mathrm{C}-\mathrm{H} \cdots \mathrm{N}$ contacts generate layers of molecules parallel to (10-1), which are $\pi \cdots \pi$ stacked in the third dimension. The packing index for 3 of $71.4 \%$ reveals a denser crystal packing than in $\mathbf{2}$. Since $\mathbf{2}$ and $\mathbf{3}$ differ only by one heteroatom site, it is possible that the weak cooperative $\mathrm{C}-\mathrm{H} \cdots \mathrm{N}$ hydrogen bonds in $\mathbf{3}$ may have a structure-directing influence.

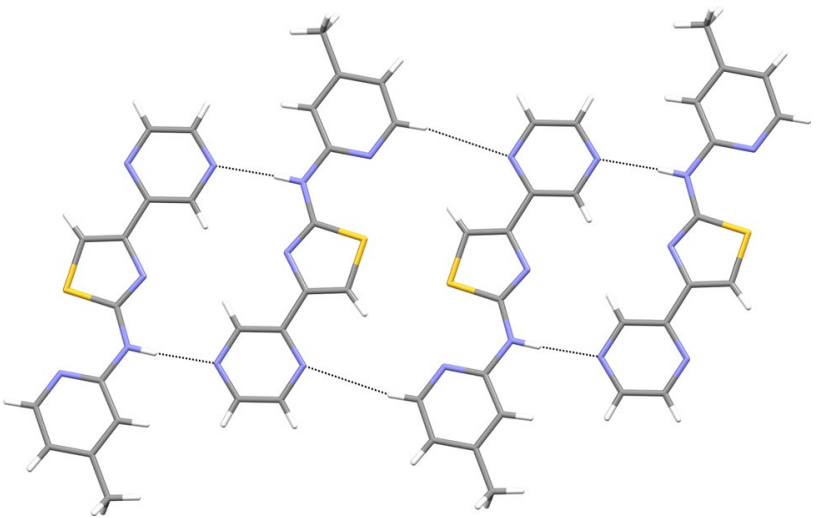

Fig. 6 Part of the crystal structure of 3 , viewed towards plane (10-1), showing two adjacent $\mathrm{N}-\mathrm{H} \cdots \mathrm{N}$ hydrogen-bonded dimers laterally connected via long $\mathrm{C}-\mathrm{H} \cdots \mathrm{N}$ contacts. Hydrogen bonds are shown by dashed lines 


\section{Conclusions}

We synthesized two pharmacologically relevant $N$,4-diaryl substituted 2-aminothiazoles via Hantzsch synthesis and elucidated their structures. Structural characterization of the starting thiourea derivative $\mathbf{1}$ revealed two crystalline forms, which exhibit distinctly different intermolecular $\mathrm{N}-\mathrm{H} \cdots \mathrm{S}$ hydrogen bonding patterns. For 2-aminothiazoles $\mathbf{2}$ and $\mathbf{3}$, the encountered synperiplanar conformation of the $\mathrm{N}$-(4-methylpyridin-2-yl)thiazol-2-amine moiety suggests the existence of supportive intramolecular $\mathrm{N} \cdots \mathrm{S}$ chalcogen bonds. Replacement of a pyridyl group in $\mathbf{2}$ by a pyrazinyl group in $\mathbf{3}$ has a significant effect on the supramolecular structures of $\mathbf{2}$ and $\mathbf{3}$ in the solid-state. Whereas $\mathbf{2}$ forms polymeric $\mathrm{N}-\mathrm{H} \cdots \mathrm{N}$ hydrogen-bonded tapes, 3 forms $\mathrm{N}-\mathrm{H} \cdots \mathrm{N}$ hydrogen-bonded cyclic dimers, which may further associate by additional weak intermolecular $\mathrm{C}-\mathrm{H} \cdots \mathrm{N}$ hydrogen bonds. Since the number of structurally characterized $N, 4-$ diaryl substituted 2-aminothiazoles is hitherto limited, the structural insight gained from this study provides impetus for further exploration of this compound class in medicinal chemistry.

\section{Supplementary Material}

CCDC 2008777-2008780 contain the supplementary crystallographic data for this paper. These data can be obtained free of charge from the Cambridge Crystallographic Data Centre via www.ccdc.cam.ac.uk/structures.

\begin{abstract}
Acknowledgements We acknowledge DESY (Hamburg, Germany), a member of the Helmholtz Association HGF, for the provision of experimental facilities. Parts of this research were carried out at the light source PETRA III and we would like to thank Dr Sofiane Saouane for assistance in using the beamline P11. Professor Christian W. Lehmann is gratefully acknowledged for his support of this project.
\end{abstract}

Author Contributions DB and AB synthesized the compounds studied and helped with the preparation of the manuscript. RG measured the X-ray diffraction data, solved the crystal structures and edited the manuscript. PI supervised the project and edited the manuscript. RWS refined the crystal structures and wrote the manuscript.

Funding Open Access funding enabled and organized by Projekt DEAL.

Data Availability Supplementary crystallographic data including reflection files have been deposited with the Cambridge Crystallographic Data Centre.

\section{Compliance with Ethical Standards}

Conflict of interest There are no conflicts of interest/competing interests to declare.
Informed Consent All authors have seen the manuscript and agree to its publication.

Open Access This article is licensed under a Creative Commons Attribution 4.0 International License, which permits use, sharing, adaptation, distribution and reproduction in any medium or format, as long as you give appropriate credit to the original author(s) and the source, provide a link to the Creative Commons licence, and indicate if changes were made. The images or other third party material in this article are included in the article's Creative Commons licence, unless indicated otherwise in a credit line to the material. If material is not included in the article's Creative Commons licence and your intended use is not permitted by statutory regulation or exceeds the permitted use, you will need to obtain permission directly from the copyright holder. To view a copy of this licence, visit http://creativecommons.org/licenses/by/4.0/.

\section{References}

1. Das D, Sikdar P, Bairagi M (2016) Recent developments of 2-aminothiazoles in medicinal chemistry. Eur J Med Chem 109:89-98. https://doi.org/10.1016/j.ejmech.2015.12.022

2. Bhuniya D, Mukkavilli R, Shivahare R, Launay D, Dere RT, Deshpande A, Verma A, Vishwakarma P, Moger M, Pradhan A, Pati H, Gopinath VS, Gupta S, Puri SK, Martin D (2015) Aminothiazoles: Hit to lead development to identify antileishmanial agents. Eur J Med Chem 102:582-593. https://doi.org/10.1016/j. ejmech.2015.08.013

3. Paquet T, Gordon R, Waterson D, Witty MJ, Chibale K (2012) Antimalarial aminothiazoles and aminopyridines from phenotypic whole-cell screening of a SoftFocus ${ }^{\circledR}$ library. Fut Med Chem 4(18):2265-2277. https://doi.org/10.4155/fmc.12.176

4. Kesicki EA, Bailey MA, Ovechkina Y, Early JV, Alling T, Bowman J, Zuniga ES, Dalai S, Kumar N, Masquelin T, Hipskind PA, Odingo JO, Parish T (2016) Synthesis and evaluation of the 2-aminothiazoles as anti-tubercular agents. PLoS ONE 11(5):e0155209. https://doi.org/10.1371/journal.pone.0155209

5. Meissner A, Boshoff HI, Vasan M, Duckworth BP, Barry CE 3rd, Aldrich CC (2013) Structure-activity relationships of 2-aminothiazoles effective against Mycobacterium tuberculosis. Bioorg Med Chem 21(21):6385-6397. https://doi.org/10.1016/j. bmc.2013.08.048

6. Makam P, Kannan T (2014) 2-Aminothiazole derivatives as antimycobacterial agents: Synthesis, characterization, in vitro and in silico studies. Eur J Med Chem 87:643-656. https://doi. org/10.1016/j.ejmech.2014.09.086

7. Gentles RG, Grant-Young K, Hu S, Huang Y, Poss MA, Andres C, Fiedler T, Knox R, Lodge N, Weaver CD, Harden DG (2008) Initial SAR studies on apamin-displacing 2-aminothiazole blockers of calcium-activated small conductance potassium channels. Bioorg Med Chem Lett 18(19):5316-5319. https://doi. org/10.1016/j.bmcl.2008.08.023

8. Khalifa ME (2018) Recent developments and biological activities of 2-aminothiazole derivatives. Acta Chim Slov 65(1):1-22. https ://doi.org/10.17344/acsi.2017.3547

9. Hantzsch A, Weber JH (1887) Ueber Verbindungen des Thiazols (Pyridins der Thiophenreihe). Ber Dtsch Chem Ges 20(2):31183132. https://doi.org/10.1002/cber.188702002200

10. Wang Z (2010) Hantzsch thiazole synthesis. In: Comprehensive organic name reactions and reagents, pp 1330-1334. https://doi. org/10.1002/9780470638859.conrr296

11. Grant SS, Kawate T, Nag PP, Silvis MR, Gordon K, Stanley SA, Kazyanskaya E, Nietupski R, Golas A, Fitzgerald M, Cho S, Franzblau SG, Hung DT (2013) Identification of novel inhibitors 
of nonreplicating mycobacterium tuberculosis using a carbon starvation model. ACS Chem Biol 8(10):2224-2234. https://doi. org/10.1021/cb4004817

12. Lim W, Melse Y, Konings M, Phat Duong H, Eadie K, Laleu B, Perry B, Todd MH, Ioset J-R, van de Sande WWJ (2018) Addressing the most neglected diseases through an open research model: the discovery of fenarimols as novel drug candidates for eumycetoma. PLOS Neglect Trop Dis 12(4):e0006437. https://doi. org/10.1371/journal.pntd.0006437

13. Goodwin H, Mather D (1972) Anomalous magnetism of iron(II) complexes of methyl-substituted pyridylthiazoles. Aust J Chem 25(4):715-727. https://doi.org/10.1071/CH9720715

14. Thomas IR, Bruno IJ, Cole JC, Macrae CF, Pidcock E, Wood PA (2010) WebCSD: the online portal to the Cambridge Structural Database. J Appl Crystallogr 43:362-366. https://doi.org/10.1107/ s0021889810000452

15. Burley SK, Berman HM, Bhikadiya C, Bi C, Chen L, Di Costanzo L, Christie C, Dalenberg K, Duarte JM, Dutta S, Feng Z, Ghosh S, Goodsell DS, Green RK, Guranovic V, Guzenko D, Hudson BP, Kalro T, Liang Y, Lowe R, Namkoong H, Peisach E, Periskova I, Prlic A, Randle C, Rose A, Rose P, Sala R, Sekharan M, Shao C, Tan L, Tao YP, Valasatava Y, Voigt M, Westbrook J, Woo J, Yang H, Young J, Zhuravleva M, Zardecki C (2019) RCSB Protein Data Bank: biological macromolecular structures enabling research and education in fundamental biology, biomedicine, biotechnology and energy. Nucleic Acids Res 47(D1):D464-D474. https://doi. org/10.1093/nar/gky1004

16. Saad FA (2014) Synthesis, spectral, electrochemical and X-ray single crystal studies on $\mathrm{Ni}$ (II) and $\mathrm{Co}(\mathrm{II})$ complexes derived from 1-benzoyl-3-(4-methylpyridin-2-yl) thiourea. Spectrochim Acta A 128:386-392. https://doi.org/10.1016/j.saa.2014.02.189

17. Cuconati A, Xu X, Block TM (2013) Preparation of substituted aminothiazoles as inhibitors of cancers, including hepatocellular carcinoma, and as inhibitors of hepatitis virus replication. WO2013052613A1

18. Amberg W, Netz A, Kling A, Ochse M, Lange U, Hutchins CW, Garcia-Ladona FJ, Wernet W (2007) Preparation of $N$-pyridin2-ylguanidines and related compounds as $5{ }^{-}{ }_{\mathrm{HT}} 5$ receptor inhibitors. WO2007022964A2

19. Gallardo-Godoy A, Gever J, Fife KL, Silber BM, Prusiner SB, Renslo AR (2011) 2-Aminothiazoles as therapeutic leads for prion diseases. J Med Chem 54(4):1010-1021. https://doi.org/10.1021/ jm101250y

20. Hung D, Serrano-Wu M, Grant S, Kawate T (2016) Substituted aminothiazoles for the treatment of tuberculosis. US20160031874A1

21. Dicks JP, Zubair M, Davies ES, Garner CD, Schulzke C, Wilson C, McMaster J (2015) Synthesis, structure and redox properties of asymmetric (Cyclopentadienyl)(ene-1,2-dithiolate)cobalt(III) complexes containing phenyl, pyridyl and pyrazinyl units. Eur J Inorg Chem 21:3550-3561. https://doi.org/10.1002/ejic.20150 0138

22. SAINT (2012) Bruker AXS Inc., Madison, Wisconsin, USA

23. Kraft P, Bergamaschi A, Broennimann C, Dinapoli R, Eikenberry EF, Henrich B, Johnson I, Mozzanica A, Schleputz CM, Willmott PR, Schmitt B (2009) Performance of single-photon-counting PILATUS detector modules. J Synchrot Radiat 16:368-375. https ://doi.org/10.1107/s0909049509009911

24. Burkhardt A, Pakendorf T, Reime B, Meyer J, Fischer P, Stube N, Panneerselvam S, Lorbeer O, Stachnik K, Warmer M, Rodig P, Gories D, Meents A (2016) Status of the crystallography beamlines at PETRA III. Eur Phys J Plus 131(3):1-9. https://doi. org/10.1140/epjp/i2016-16056-0
25. Kabsch W (2010) XDS. Acta Crystallogr D 66:125-132. https:// doi.org/10.1107/s0907444909047337

26. SADABS (2012) Bruker AXS Inc., Madison, Wisconsin, USA

27. Sheldrick GM (2015) SHELXT-integrated space-group and crystal-structure determination. Acta Crystallogr A 71(Pt 1):3-8. https://doi.org/10.1107/S2053273314026370

28. Sheldrick GM (2015) Crystal structure refinement with SHELXL Acta Crystallogr C 71(Pt 1):3-8. https://doi.org/10.1107/S2053 229614024218

29. Lübben J, Wandtke CM, Hübschle CB, Ruf M, Sheldrick GM, Dittrich B (2019) Aspherical scattering factors for SHELXLmodel, implementation and application. Acta Crystallogr A 75(Pt 1):50-62. https://doi.org/10.1107/S2053273318013840

30. Kissel L, Pratt RH (1990) Corrections to tabulated anomalousscattering factors. Acta Crystallogr Sect A 46(3):170-175. https ://doi.org/10.1107/S0108767389010718

31. APEX3 (2018) Bruker AXS Inc., Madison, Wisconsin, USA

32. Spek AL (2020) checkCIF validation ALERTS: what they mean and how to respond. Acta Crystallogr E 76(Pt 1):1-11. https://doi. org/10.1107/S2056989019016244

33. Brandenburg K (2018) DIAMOND. 3.2k3 edn. Crystal Impact GbR, Bonn, Germany

34. Macrae CF, Sovago I, Cottrell SJ, Galek PTA, McCabe P, Pidcock E, Platings M, Shields GP, Stevens JS, Towler M, Wood PA (2020) Mercury 4.0: from visualization to analysis, design and prediction. J Appl Crystallogr 53 (Pt 1):226-235. https://doi. org/10.1107/S1600576719014092

35. Tutughamiarso M, Bolte M (2007) 1-(Pyridin-2-yl)thiourea. Acta Crystallogr E 63(12):o4682-04682. https://doi.org/10.1107/s1600 536807057388

36. Etter MC (1990) Encoding and decoding hydrogen-bond patterns of organic-compounds. Acc Chem Res 23(4):120-126. https://doi. org/10.1021/ar00172a005

37. Bernstein J, Davis RE, Shimoni L, Chang NL (1995) Patterns in hydrogen bonding - functionality and graph set analysis in crystals. Angew Chem-Int Edit 34(15):1555-1573. https://doi. org/10.1002/anie.199515551

38. Steed KM, Steed JW (2015) Packing problems: high Z' crystal structures and their relationship to cocrystals, inclusion compounds, and polymorphism. Chem Rev 115(8):2895-2933. https ://doi.org/10.1021/cr500564z

39. Kitajgorodskij AI (1973) Molecular crystals and molecules. Academic Press, New York

40. Scilabra P, Terraneo G, Resnati G (2019) The chalcogen bond in crystalline solids: a world parallel to halogen bond. Acc Chem Res 52(5):1313-1324. https://doi.org/10.1021/acs.accounts.9b00037

41. Vogel L, Wonner P, Huber SM (2019) Chalcogen bonding: an overview. Angew Chem Int Ed 58(7):1880-1891. https://doi. org/10.1002/anie.201809432

42. Groom CR, Bruno IJ, Lightfoot MP, Ward SC (2016) The cambridge structural database. Acta Crystallogr B 72(Pt 2):171-179. https://doi.org/10.1107/S2052520616003954

43. Roy S, Quinones R, Matzger AJ (2012) Structural and physicochemical aspects of dasatinib hydrate and anhydrate phases. Cryst Growth Des 12(4):2122-2126. https://doi.org/10.1021/cg300152p

44. Sarcevica I, Grante I, Belyakov S, Rekis T, Berzins K, Actins A, Orola L (2016) Solvates of dasatinib: diversity and isostructurality. J Pharm Sci 105(4):1489-1495. https://doi.org/10.1016/j. xphs.2016.01.024

45. Ries O, Granitzka M, Stalke D, Ducho C (2013) Concise synthesis and X-ray crystal structure of $N$-Benzyl-2-(pyrimidin-4'-ylamino)thiazole-4-carboxamide (Thiazovivin), a small-molecule tool for stem cell research. Synth Commun 43(21):2876-2882. https://doi. org/10.1080/00397911.2012.745567 
46. Thakuria R, Sarma B, Nangia A (2017) 7.03-Hydrogen bonding in molecular crystals. In: Atwood JL (ed) Comprehensive supramolecular chemistry II. Elsevier, Oxford, pp 25-48. https://doi. org/10.1016/B978-0-12-409547-2.12598-3
Publisher's Note Springer Nature remains neutral with regard to jurisdictional claims in published maps and institutional affiliations.

\section{Affiliations}

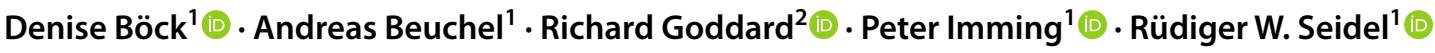

1 Martin-Luther-Universität Halle-Wittenberg, Institut für Pharmazie, Wolfgang-Langenbeck-Str. 4, 06120 Halle (Saale), Germany
2 Max-Planck-Institut für Kohlenforschung, Kaiser-Wilhelm-Platz 1, 45470 Mülheim an der Ruhr, Germany 